\title{
The value of public green spaces and the effects of South Africa's informal backyard rental sector
}

\author{
L. G. Lategan \& E. J. Cilliers \\ Unit for Environmental Sciences and Management, \\ Urban and Regional Planning, North-West University, South Africa
}

\begin{abstract}
This paper investigates the effects of the informal backyard rental sector on the green space made available to tenants and landlords in South Africa. This research explores the hypothesis that backyard dwellings and their encroachment on private outside space necessitate the development of a greater number of qualitative public green spaces. The case study of Bridgeton in Oudtshoorn, South Africa, showcases a variety of housing projects delivered during and after the Apartheid regime. Interviews with authorities and residents and an extensive survey provide valuable insight. This paper concludes that the informal backyard rental sector occupies the private open space intended to be used by landlords who live in formal dwellings. Backyard tenants also increase living densities, intensifying the need to find new venues for recreational activities further afield. The problem is exacerbated by the poor quality and limited accessibility associated with the public green spaces delivered in most low-income communities
\end{abstract}

Keywords: high-density development, informal backyard renting, public green space, South African cities.

\section{Introduction}

South Africa's Apartheid policy forced segregated and uneven development, ultimately producing the fragmented cities inhabited today. Apartheid not only influenced urban development during its oppressive reign, between 1948 and 1994, but left a legacy of segregation, which has been difficult to reverse. Ever since, South African planners have faced an incessant increase in the demand for 
low-cost housing, restricted resources to meet needs and an urban structure that is segregated according to income level and ethnicity. Since the advent of democracy in 1994, low-cost housing delivery has mostly involved building serviced townships on urban peripheries, thus perpetuating the phenomenon of urban sprawl and the ails associated therewith [1,2]. Apartheid produced a wasteful urban structure that generated a disseminated settlement arrangement, which still hinders service provision and access to socio-economic and cultural amenities in the contemporary South African city [3].

The housing shortage and the unsuitable locations sourced for the development of low-income projects, have forced 712,956 South Africans into the backyards of their subsidy-housed compatriots [4].

\section{The backyards of the Republic}

As a result of historic and recent urban development, a uniquely South African phenomenon has manifested itself. The informal backyard sector can be observed in South African settlements, in urban centres and even in more rural locations where formal housing has been provided by the state [5]. The sector provides essential shelter to those waiting to be housed by the South African government's Reconstruction and Development Programme (RDP). Given the housing delivery backlog, rapid urbanization, restricted institutional capacity, limited funding and wide-spread corruption, South Africa's otherwise displaced have turned to the informal rental market as a temporary residence. However, these dwellings represent a more permanent residence for some. SDMS [6] states that $25 \%$ of backyard renters believe that they are destined to call backyard dwellings home for the rest of their lives.

The informal backyard rental sector has established itself as a distinctive element of the country's urban landscape and as an equally substantial contributor to South Africa's housing stock. The backyard rental phenomenon was established in the 1980s in response to the shortage of satisfactory accommodation close to the socio-economic opportunities provided by more developed urban centres in lure of negligent state regulation [7]. Government's tolerance soon cultivated a culture of unofficial and unintended acceptance, securing land invasions as a common component of South African development culture by the mid-1980s. According to Crankshaw et al. [8] the pre-1994 South African government accepted the extensive establishment of informal structures in order to compensate for the shortage of housing units delivered. The peripheral locations of most subsidized housing schemes delivered in the post-Apartheid era only intensified the established trend of informal renting. The backyard sector is defined by informal shanty structures that occupy surplus space, shared with a formally developed housing unit within a formal and fully serviced housing area [13]. Watson [9] states that two categories of backyard dwellings can be observed. Referring firstly to structures built by landlords to rent to tenants. Secondly referring to structures built by tenants on spaces rented from landlords, mainly in the informal sector. 
The latter is a uniquely South African manifestation, which distinguishes the local backyard sector from examples in other developing countries [8].The shelter provided by backyard structures is generally insufficient, unsustainable and detrimental to overall well-being. Morange [10] states that backyard structures mainly consist of one or two rooms, crudely constructed from wood or corrugated iron and insulated with cardboard. According to Lemanski [11], backyard dwellings are often shared by both sexes and all ages of one or more families, and used for all daily living activities.

The physical structures occupied by backyard renters are comparable to the dwellings found in the marginalised informal townships located across South Africa. However, one main benefit distinguishes the two: backyard renters still enjoy some access to the services provided to their landlords, including access to public green spaces. The Social Housing Foundation [11] states that in general, backyard settlers enjoy better access to services than those in informal settlements, albeit to a limited extent due to restrictions imposed by landlords and general overcrowding. According to Poulsen and Silverman [12], backyard rooms increase residential densities, thereby combatting urban sprawl and making more effective use of existing infrastructure investments. However, the extreme establishment of backyard accommodation and the sector's dense spread throughout South Africa has placed an immense burden on the infrastructure networks already established. In addition, the increase in residential densities, which are not supported by layout plans geared towards low density, detached housing typologies has increased pressure on mostly underdeveloped and inaccessible public amenities such as parks, sports fields and naturally vegetated areas. This drastically affects quality of life in areas where South Africa's unemployed are left to etch out their bleak daily lives; a fact that became increasingly apparent in the case study of Bridgeton, South Africa.

\section{Bridgeton, Oudtshoorn, South Africa}

The town of Oudtshoorn is located in the Garden Route, a picturesque part of South Africa's Western Cape Province. Oudtshoorn is home to 95,933 people and covers a total area of $29.24 \mathrm{~km}^{2}$ [5]. The research conducted for this paper focused specifically on an area of approximately $220,000 \mathrm{~m}^{2}$, located in Bridgeton, a township established during Apartheid for members of Oudtshoorn's population, classified under Apartheid as 'Coloured'. The study area comprises a large and recently redeveloped sports stadium of about $90,000 \mathrm{~m}^{2}$ and the 100 households surrounding it. Homes here are located on stands with an average size of $325 \mathrm{~m}^{2}$. The study area was selected because it represents a mix of dwellings developed both during and after Apartheid, possesses a fair number of backyard dwellings, provides residents with access to public green space within their immediate vicinity and because it represents a large investment in public green amenities within low-cost communities.

Research entailed interviews with various residents and officials from local government, selected on the basis of their involvement in the area, as well as a 
questionnaire, distributed to one hundred households surrounding the stadium. A one hundred percent return rate was ensured by conducting the survey on a doorto-door basis. However, the number of questionnaires distributed was restricted by the volatile nature of the area and subsequent need to employ members of the local neighborhood watch as chaperones. Survey results were processed by the Statistical Consultancy Services offered by the North-West University to ensure accuracy and simplified interpretation.

The following section will attempt to discuss the research topic, supported by interview and survey findings.

\section{Coming to terms with public green space}

Green spaces may reinforce the identity of urban centres and heighten the allure of towns and cities as places to live, work and invest in; in essence, thus contributing to quality of life and competitiveness [13]. According to Caspersen et al. [14], it has been well established that urban green areas provide varied socioeconomic, environmental and aesthetic benefits. Van Leeuwen et al. [13] state that green space in an urban setting is a central element in improving urban quality of life.

The Oudtshoorn Local Municipality recognizes the importance of green amenities and as such redeveloped the Bridgeton Stadium from a rugby field, which was only used by the local community, to a sporting facility, which regularly hosts comparatively large sporting events and attracts a large and diverse audience [15]. As such, the stadium has become an important tool in Oudtshoorn's social integration toolbox. This is especially prevalent when one considers the limited access to green space conventionally provided in South Africa's lowincome suburbs. According to CABE [16], it is a global reality, in both developing and developed countries, that residents in deprived areas have limited access to parks and other green spaces, whilst their counterparts in more prosperous neighbourhoods are better serviced. This divide is often recognizable according to inequalities between economic and ethnic divides. CABE [16] states that the experience of nature is universally restorative and connected with improved emotional welfare, regardless of ethnicity or culture. Recreation is as much part of a fulfilled life in minority and poorer groups as it is in more affluent groups and majorities. Few are as deprived and divided as those who live in rented accommodation in South Africa's backyards.

In South Africa a definite correlation can be found between income-level and access to public green spaces. In more affluent suburbs, the lowest density housing options and the greatest area of green space per capita are common. On the other hand, Reconstruction and Development Programme (RDP) developments delivered in the post-Apartheid era, are poorly endowed with green space and accompanying amenities [17].

Conversely, older suburbs developed during the Apartheid regime, although not the proverbial walk in the park either, seem to provide relative consideration for green amenities. According to Eastes [15], in the older portions of Bridgeton most residents can find a park within $1.8 \mathrm{~km}$ of their residence. Whether or not 
these amenities are still accessible today and will remain open in future is another question [17]. The rapid urbanization and high rates of population growth found in South Africa, and subsequent demand for housing and suitable land, often make existing green spaces the target of land invasions or development. It is precisely this demand which has facilitated and cultivated the development and sustained growth of the informal backyard rental sector [19]. Although land invasions are a common sight in South Africa, these land grabs are more focused on vast stretches of undeveloped land rather than on the confines of smaller parks and other protected green spaces within the urban edge [5]. As an example, informal settlements in Oudtshoorn are limited to those found in the backyards of Bridgeton and neighbouring Bongulethu and the invaded stretch of previously uninhabited and environmentally sensitive land, now known as the Rose Valley informal settlement. Whilst other smaller parks and green spaces remain unsettled.

However, the absence of informal structures on these parks is also accompanied by an absence of users. En route to the stadium, one passes two or three smaller play parks, all gated, fenced and topped with razor wire. It seems that no matter the size, location or nature of the green area provided, a singular unifying factor can be identified: restricted access, if any at all. Surveys showed a discrepancy regarding the use of the local stadium. Some (28.7\%) claim that facilities are always accessible, $68.3 \%$ that they are only free to make use of facilities by attending sporting events at an admittance charge and others that entrance can only be gained by sneaking in through an open gate or by scaling the wall of corrugated iron sheeting surrounding the stadium. In addition, the unattractive corrugated iron wall prohibits the community from benefiting from the aesthetic value offered by the stadium's greenery. Eastes [15] states that the corrugated steel barrier was kept after redevelopment as it has become synonymous with the area's character and as such has been transformed into a landmark - hardly the epitome of a welcoming place for children and the rest of the community to enjoy the limited, but well maintained facilities found there. According to Eastes [15], play parks were closed off on request from the community in order to protect facilities from criminals and salvagers in search of steel and wood to sell to local salvage yards or to use in the construction of their backyard dwellings. When accessible at any time, parks become hotpots for drug use and gang meetings, activities understandably despised by residents and authorities, meriting park closures [19].

\section{Green space, informality and crime}

Public green spaces seem to provide the perfect venues for illicit activities. As a result, many RDP and township residents prefer public green spaces that provide sport facilities and dislike green areas that are densely vegetated. Lush vegetation provides space for criminals to hide and carry out their criminal acts [20]. Personal safety or the perception thereof is a deciding factor in the usage of green space across all ethnicities and communities. As such, perceptions of personal safety can indirectly influence health through the disposition to make use of public green spaces [16]. 
Residents around the Bridgeton Stadium reported reduced crime levels, which seemingly coincide with the redevelopment of the stadium and an increased police presence. However, crime is still a major problem and Muller Street, located adjacent to the Stadium, remains infamous in the area. Residents reported contact with crimes in the following manner of regularity:

- $80.2 \%$ reported coming into contact with or hearing about substance abuse in their immediate area on a daily basis.

- $63.2 \%$ reported coming into contact with or hearing about gang-related violence and behaviour in their immediate area on a daily basis.

- $44.6 \%$ reported coming into contact with or hearing about muggings and robberies in their immediate area on a daily basis.

- $14.9 \%$ reported coming into contact with or hearing about sexual assault in their immediate area on a daily basis.

- $13.9 \%$ reported coming into contact with or hearing about murders in their immediate area on a daily basis.

The informal backyard rental sector also contributes its share of crime and violence statistics, driven by alcohol and narcotic abuse [19]. It is thus permissible to suggest that many of the worrying behaviours associated with poverty and unemployment, related to backyard living, find a venue for expression and intensification where public green spaces are poorly maintained and used. Green spaces that provide play and sporting facilities may counter the negative connotations often related to green spaces in lower-income areas. These facilities provide spaces with a useful purpose, which may prevent negative behaviour such as criminal activity, underage drinking, substance abuse and violence [20], which are all regularly associated with the informal backyard rental sector [19]. CABE [16] states that access to quality green spaces can also improve cognitive restoration and self-discipline, may reduce aggression and lower crime levels, dependent on the measures and amenities provided. Thus, the success of a green space in combatting crime and unwanted behaviour is related to the quality of the space provided and the nature of the facilities, including play and sporting facilities and vegetation, found there.

\section{Greening for environmental benefits}

In addition, green spaces, especially when vegetated with trees and shrubbery, may help mitigate the impacts imposed on the environment by urban development. Urban greenery may moderate climates, conserve energy, reduce carbon dioxide in water, improve air quality, control rainfall runoff and flooding, reduce levels of erosion, provide shading, reduce noise levels and also provide habitats for wildlife $[13,21]$; thus combatting the pressure exerted by the sometimes extreme densities associated with the informal backyard rental sector and the structures built to house tenants. Some stands in the study area displayed extreme densities. For example, the property represented by survey sheet 136 displayed a total occupancy size of 26 persons of various ages, 14 of whom stayed in backyard structures. Affluent South African suburbs enjoy lower household densities when compared to their lower-income counterparts in both RDP projects and townships [17]. 
Increased household densities further increase pressure on public green space and lower per capita provisions. Backyard dwellings not only exert increased pressure on existing facilities, but also place restrictions on the backyard spaces intended to accommodate private gardens. The value of public green space is amplified in residential areas where stand sizes do not provide adequate private space [17].

In the Bridgeton case study, residents' gardens reflected the following:

- Only 33\% of residents planted and maintained a lawn.

- $60 \%$ maintained trees on their properties.

- $42 \%$ had planted vegetables.

- $82 \%$ planted and maintained flower beds.

It should also be noted that $56 \%$ of residents felt that the presence of backyard structures on their properties limited their private space and the area available to them to cultivate their own gardens and vegetable patches. Thus, it could be surmised that the establishment of community vegetable gardens in order to compensate for the private space lost would be prudent. However, in Bridgeton past attempts at establishing community vegetable gardens have been disastrous, largely due to a lack of water suitable for irrigation, as drinking water is too expensive and scarce in this semi-arid Klein Karoo town [15]. Also, it is largely due to the nature of the community in question, where idleness, unemployment, vandalism and crime run rampant.

The green elements of public green spaces seem to be of the utmost importance to residents, thus inferring an appreciation for the aesthetic values presented by public green spaces. In the Bridgeton survey, the following was observed in relation to an adequate public green space:

- $97 \%$ rated landscaped lawns as critical.

- $95 \%$ rated shade trees as critical.

- $49.5 \%$ rated landscaped gardens as critical.

- $21.2 \%$ rated water features as critical.

From an environmental perspective, backyard dwellings may infer certain dangers. Bridgeton's backyard structures are primarily constructed from tarred wood salvaged from local timber yards. At night, structures are lit with candles or informal electrical connections, which make house fires a common occurrence [22]. These fires spread rapidly from yard to yard and not only cause fatalities but also air pollution. Public green spaces may provide venues for communities to gather when fires surge through their neighbourhoods, thus providing a safe harbour.

In addition, low-income areas are prone to excessive littering, which is seemingly increased in the informal backyard rental sector, which is often forced to dispose of its waste without dedicated help from municipalities. In an attempt to counter the spread of refuse, the City of Cape Town is currently piloting an infrastructure upgrading program for backyard dwellings, which includes the distribution of additional refuse bins to tenants [23]. Where measures are not put in place, public green spaces may become dumping grounds, thus inferring a need for adequate upkeep and supervision. In Bridgeton, 57\% of survey participants rated littering as a problem that affects their lives on a daily basis around the stadium. 
In principle, the provision of quality green spaces improves environmental sustainability. As is well documented, sustainability is a three-pronged concept, which can only be achieved when environmental, economic and social aspects are well balanced and equally prioritised.

\section{Public green spaces: social magnets for healthy communities}

In relation to social integration, CABE [16] states that green spaces can facilitate regular interaction between different people, which may provide the platform for the beginnings of a community. The Bridgeton Stadium was specifically redeveloped intensively not only to service the Bridgeton and Bongulethu communities, but also to draw users from the entire town of Oudtshoorn. In this regard the stadium acts as one of the few, if not the only, venues for integration in the town, by bridging the social divide between shack dwellers and backyard renters and those who reside in Oudtshoorn's affluent leafy suburbs [15]. However, perceptions of danger still deter many wealthier visitors, thus maintaining the chasm between economic classes and different ethnicities established during Apartheid.

Green space has been proven to intensify the strength of a community by reducing the impact of deprivation and improving health and general wellbeing. As such, access to quality green space is related to reduced mortality levels by reducing the risk of depression and lung disease, which may reduce the disparity in life expectancy between the wealthy and the poor [16]. This is especially prevalent given the poor health associated with backyard living. Backyard rooms are generally very poorly ventilated due to a lack of windows and inefficient flooring options $[24,25]$. The lack of cross ventilation manifests as respiratory ailments such as tuberculosis and lung infections. Thus, it is vital that public green spaces provide access to fresh air and promote physical activity to combat the health implications related to backyard living. According to RWJF [26], residents of more walkable neighbourhoods, including neighbourhoods with public green spaces that promote walkability, partake in 35 to 45 more minutes of moderateintensity physical activity per week. However, survey results showed that only $20 \%$ of Bridgeton participants owned motor vehicles and are subsequently dependent either on expensive public transport or on pedestrian movement. Thus, whilst providing walkable and pedestrian safe neighbourhoods remains essential, in South African communities like Bridgeton, when it comes to public spaces, it is less about encouraging pedestrian movement and more about providing a destination that merits long pedestrian journeys. The survey showed that $61 \%$ of participants were willing to walk more than $5 \mathrm{~km}$ to access a quality green space that offered activities and access to nature.

As always, the economic dimension of planning, to a large extent guided by the economic profile of the community of end-users in question, prescribes what is planned and ultimately delivered. 


\section{Making sense of green economics}

'The economic value of nature can be defined as the total amount of welfare that nature generates for society' [27]. Accordingly, the benefits related to urban green space cannot be limited to direct financial advantages. Distinction should rather be made between economic and financial values. Economic values refer to externalities that do not involve money transfers; whilst financial values denote the market prices paid for goods. Urban greenery and parks rarely deliver harvestable goods that can be measured by a direct economic return [28]. In fact, green spaces require investment by a multitude of stakeholders and deliver intangible benefits to the broader community and users.

According to Van Leeuwen et al. [13], urban green spaces may contribute to the economic strength of an area by generating employment opportunities and particularly by increasing aesthetic appeal, which in turn increases property values. According to Wolf [28], economists have developed models that capture the value of public goods such as green spaces. The value of green space is best measured according to non-market valuation techniques such as the hedonic valuation approach, which measures the full direct and indirect value of parks [29]. According to RWJF [26], the impact exerted by green spaces on residential property values depends on distance, total green space area and neighbourhood characteristics. A valuation method based on house price relies on the premise that a stable and formal property market exists. In areas where the property market might be unstable to non-existent, the importance of intangible benefits is intensified. According to Cronje [30], in Bridgeton houses are bought and sold, but for prices that do not seem to reflect market related values. For instance, identical houses located directly next to each other may fetch prices that differ tremendously, dependent on the seller's perception of worth and the buyer's willingness to pay. It is interesting to note here that $63 \%$ of survey participants stated that if they were in a fortunate enough position to purchase a house, they would be willing to pay more for a property simply because it was located closer to a green amenity.

The hedonic valuation approach relies on property values and correlation to increased property taxes collected by local authorities [29]. Local authorities must always keep in mind that the level of property tax revenue generated by a green open space will depend on the built environment surrounding it [26]. In the Bridgeton case study, $97 \%$ of participants claimed to pay property tax. According to Eastes [15], as with any neighbourhood or urban region, property tax in Bridgeton is calculated according to property value. However, property value is not always easy to establish [15]. In Bridgeton property-specific attributes such as condition and extensions influence municipal property valuations much more than location. Thus, permanent attributes may increase property value more than location in proximity to public green spaces. Subsequently, for the purpose of this paper it is important to discuss the contribution of the informal backyard rental sector to property value. According to RWJF [26], the potential economic benefits related to green spaces in suburbia are increased as population density increases. It is well established that the informal backyard rental sector increases 
residential densities [18]. However, as backyard dwellings by their very nature are temporary structures and a common sight in SA's low-income suburbs, whether or not they contribute to or detract from property value is debatable. It is surmised that it is rather the availability of space to erect backyard structures that may increase property value. Furthermore, backyard residents only pay rent and not additional property taxes, implying that the sector's contribution to governmental income in this regard is limited. Thus, the presence of informal backyard rental units in proximity to public green spaces may not increase the worth of these spaces from a financial perspective, but may prove very valuable when economic significance is considered.

\section{Conclusion}

In conclusion, it becomes clear that public green spaces play an important part in maintaining sustainable communities. Public green spaces do not always provide direct financial benefits, but their contribution to the well-being of society and the environment are unmistakable. These benefits are intensified where a larger number of users can make use of the facilities offered, as inferred by the increased densities imposed by South Africa's informal backyard rental sector. The private backyard space occupied by backyard structures and the poor living conditions associated with backyard renting provide evidence for the need to develop public green spaces that provide sufficient access and amenities of an acceptable quality. In a society plagued by poverty and crime, ensuring the safety of users and the longevity of investments in public green spaces are essential. The Bridgeton case study confirmed that all members of society, landlords and tenants alike, value the importance of public green spaces that offer both aesthetic appeal and communal facilities, especially where informal renting intrudes on private space. It also proved that communities would go as far as to deny themselves access to these spaces in order to protect amenities from their peers, thus inferring a sense of ownership and pride in the green spaces that offer refuge in the dense concrete and corrugated iron South African suburb. In this regard, public green space planning needs to become a main focus in low-cost housing development, especially when the informal backyard rental sector is considered as an unavoidable symptom of post-Apartheid development.

\section{Acknowledgements}

This research (or parts thereof) was made possible by the financial contribution of the NRF (National Research Foundation) South Africa. The opinions, findings and conclusions or recommendations expressed in this material are those of the authors and therefore the NRF does not accept any liability in regard thereto. 


\section{References}

[1] Goebel, A., "Sustainable urban development? Low-cost housing challenges in South Africa", Habitat International, 31(3-4), pp. 291-302, 2007.

[2] Fieuw, W.V.P., "Informal Settlement Upgrading in Cape Town's Hangberg: Local Government, Urban Governance and the 'Right to the City", Master of Philosophy, Faculty of Economics and Management Sciences, Stellenbosch University.

[3] Makamu, R.I., "Background of housing delivery process in South Africa", University of Limpopo, pp. 1-113, 2010.

[4] STATSSA, "CensusinBrief." http://www.statssa.gov.za/census2011/Products/Census_2011_Census_in brief.pdf

[5] Lategan, L.G. \& Ciliers, E.J., "An exploration of the informal backyard rental sector in South Africa's Western Cape Province." ISOCARP Congress: Evolving and Declining Models of City Planning practice, Brisbane, 2013, pp. 1-12.

[6] SDMS, Shishaka Development Management Services 2006. http://www.shisaka.co.za/

[7] Ebrahim, Z., Social Housing Regulatory Authority: State of the sector. www.sahf.org.za/Images/2011\%20Proceedings/PowerPoints/Zohra_Ebrah im.pdf

[8] Crankshaw, O., Gilbert, A. \& Morris, A., "Backyard Soweto”, International Journal of Urban and Regional Research, 24(4), pp. 841-857, 2000.

[9] Watson, V., Strategic literature assessment for informal rental research project: Report to the Social Housing Foundation 2009. .http://www.urbanlandmark.org.za/downloads/small_scale_rental_report_ watson_2010.pdf

[10] Morange, M., "Backyard shacks: the relative success of this housing option”, Urban Forum, 13(2), pp. 3-25, 2002.

[11] Lemanski, C., Augmented informality: South Africa's backyard dwellings as a by-product of formal housing policies. Habitat International, Volume 33, Issue 4, pp. 472-484, 2009.

[12] Poulsen, L. \& Silverman, M., "Design strategies for the densification of low income housing, Congress on housing: Transforming housing environments through design." University of Pretoria, pp. 27-30, 2005.

[13] Van Leeuwen, E., Nijkamp, P. \& de Norohna Vaz, T., "The multi-functional use of urban green space." Amsterdam, pp. 1-13, 2009.

[14] Caspersen, O.H., Konijnendijk, C.C. \& Olafsson, A.S., "Green space planning and land use: An assessment of urban regional and green structure planning in Greater Copenhagen." Danish Journal of Geography, 106(2): 7-20, 2006.

[15] Eastes, J., Personal communication, 11 November 2013, Chief Town Planner: Oudtshoorn Local Municipality, Oudtshoorn, SA.

[16] CABE, Report on Community green: using local spaces to tackle inequality and improve health, pp. 1-66, 2010. 
[17] Mcconnachie, M.M. \& Shackleton, C.M., "Public green space inequality in small towns in South Africa." pp. 1-10.

[18] Lategan, L.G. \& Cilliers, E.J., "South Africa's informal backyard rental sector: Linkages with Smart Growth and sustainability concepts." Wessex Institute of Technology Sustainable City 2013 Conference, Putrajaya, pp. 1-12, 2013.

[19] Nortje, C., Personal communication, 2 May 2013, SAPD Sector Commander: Bridgeton, Oudtshoorn, SA.

[20] Walton, W., Jevon, T., Simmons, A., Khan, N., Schackleton, R., De Lacy, P. \& Sholto-Douglas, C., "An economic and condition analysis of public urban green spaces in Grahamstown, Eastern Cape." Department of Environmental Science, Rhodes University, Grahamstown, pp. 1-47, 2012.

[21] Liu, S. \& Hite, D., "Measuring the Effect of Green Space on Property Value: An Application of the Hedonic Spatial Quantile Regression." (SAEA) Annual Meeting, Orlando, Florida, pp. 2-40, 2013.

[22] Julies, Personal communication, 4 May 2013, Housing beneficiary. Oudtshoorn, SA.

[23] Mitchell, T., 2013. Head of Housing Policy and Research, City of Cape Town. [Personal Interview]. 6 May 2013. Cape Town.

[24] Crouse, P., Personal communication, 3 May 2013, Health Inspector: Oudtshoorn, SA.

[25] Andries, A., Personal communication, 3 May 2013, Health Inspector: Oudtshooorn, SA.

[26] Robert Wood Johnson Foundation., RWJF, "The Economic Benefits of Open Space, Recreation Facilities and Walkable Community Design." Active Living Research, pp. 1-28, 2010.

[27] Rodenburg, C., Baycan-Levent, T., van Leeuwen, E. \& Nijnkamp, P., "Urban Economic Indicators for Green Development in Cities." European Union project on the Development of Urban Green Spaces (URGE), pp. 1-16, 2001.

[28] Wolf, K.L., "Public Value of Nature: Economics of Urban Trees, Parks and Open Space.” In: Miller, D. \& J. A. Wise, 2004, Design with Spirit: Proceedings of the 35th Annual Conference of the Environmental Design Research Association. Edmond, OK: Environmental Design Research Association, pp. 1-5, 2004.

[29] Shaikh, S.B., "The Economic Impact of Urban Green Space Investments: A Case Study for Chicago" Program on Global Environment and Public Policy Studies, University of Chicago, pp. 3-17, 2011.

[30] Cronje, J.A.S., Personal communication, 11 November 2013, Official property valuer: Oudtshoorn Local Municipality, Oudtshooorn, SA. 